\title{
Long-term follow-up after intravenous injection of massive volume of mercury: A case report
}

\author{
Yinglu Hao, Yanping Li
}

\begin{abstract}
Introduction: Mercury is the only metal that exists in liquid form at room temperature. It has no essential biological function. It is used in manufacturing switches, thermometers, and sphygmomanometers. Mercury is also used in extraction of gold and silver. Besides, it is used in pesticides and tooth fillings. Exposure to mercury can cause mercury poisoning which is also known as hydrargyria or mercurialism. Exposure can be by inhalation, ingestion or injection. Self-injection of mercury is very rare but is well documented. Although hydrargyrism has been reported well hydrargyrism via intravenous injection is rarely reported. Here we present a case of a 19-year-old boy who injected himself with massive volume of metallic mercury. Case Report: A 19-year-old man injected himself intravenously in the left elbow with about $15 \mathrm{ml}$ of metallic mercury. He complained of dizziness, chest tightness, hemoptysis, dyspnea, malaise, sweating, soreness of waist and bloody sputum for a day and was sent to the hospital immediately. $X$-ray showed a large number of scattered metalic substance in bilateral lung fields, and distributed along vascular channelsall over the body. He was treated with large dose of DMPS and supportive therapy, but he expired after two hospitalizations in eight months. Conclusion: In cases of hydrargyrism with huge volume,
\end{abstract}

Yinglu $\mathrm{HaO}^{1}$, Yanping $\mathrm{Li}^{1}$

Affiliations: ${ }^{1}$ Department of Cardiology, People's Hospital of Yuxi City, Yunnan Province

Corresponding Author: Yinglu Hao, Department of Cardiology, People's Hospital of Yuxi City, Yunnan Province; Email: yingluhao@aliyun.com

Received: 22 February 2016

Accepted: 15 May 2016

Published: 07 July 2016 only drug therapy may not enough. Vascular intervention therapy maybe more effective in acute period, which can remove the residual of mercury. This may improve the clinical outcome.

Keywords: Hydrargyrism, Intravenous injection, Outcome

\section{How to cite this article}

Hao Y, Li Y. Long-term follow-up after intravenous injection of massive volume of mercury: A case report. Case Rep Int 2016;5:27-30.

Article ID: 100026CRINTYH2O16

$* * * * * * * * *$

doi:10.5348/crint-2016-26-CR-7

\section{INTRODUCTION}

It is reported that mercury poisoning wisas more common via respiratory or digestive routes and less common by skin contact [1]. However, it is rarely seen via intravenous injection. In this case, we present a case with long-term follow-up after injection of metallic mercury.

\section{CASE REPORT}

In september 2002, a 19-year-old male injected himself in the left elbow with about $15 \mathrm{ml}$ of metallic mercury after a quarrel with his parents. He complained of dizziness, chest tightness, hemoptysis, dyspnea, malaise, sweating, soreness of waist, and bloody sputum was concious and for a day when he was admitted. On examination, the patient had fever of $39.40^{\circ} \mathrm{C}$. Breath 
sounds of both his upper lungs sounded rough and decreased in lower lung by chest auscultation. Respiration rate was 20/min. His heart rate was $108 \mathrm{bpm}$, without any arrhythmia or cardiac murmur. Blood pressure of $100 / 80$ with no signs of shock. No tenderness in abdomen, liver and spleen were palpable. X-ray showed a large number of light metal substance in bilateral lung fields, distributed along the pulmonary vasculature, and a large number of light metal substance in right atrium and ventricles (Figures 1-2). There was a large area of dense shadow along vascular bed in the abdomen (Figure 3), pelvis and scrotum (Figure 4). Massive deposits were found along the hepatic central venous channels. A radioopaque shadow of $0.5^{-1} \mathrm{ml}$ was seen in the left elbow. There was no abnormaling observed in brain, right limbs and both lower limbs.

Laboratory examination showed: Glutamate pyruvate transaminase (ALT): 29 IU/L, glutamic oxaloacetase transaminase (AST) $43 \mathrm{IU} / \mathrm{L}$, lactic dehydrogenase (LDH): 424 IU/L, lactic dehydrogenase-1 (LDH1): 248 IU/L, creatine kinase (CK): 440 IU/L, creatine kinaseMB (CK-MB): 19U/L, urea nitrogen (BUN): $8.4 \mathrm{mmol} / \mathrm{L}$, creatinine (Cr): $03 \mu \mathrm{mol} / \mathrm{L}$, urine acid (UA): $424 \mu \mathrm{mol} / \mathrm{L}$. Blood tests showed: white blood cell (WBC): $13.0 \mathrm{~g} / \mathrm{L}$, neutrophiles $77.4 \%$, lymphocyte: $14.4 \%$, macrocyte: $8.2 \%$. The mercury in the urine was $458 \mathrm{nmol} / \mathrm{L}$, with a normal routine urinalysis. From the symptoms and examinations, he was diagnosed as:

i. Acute mercury poisoning via intravenous injection;

ii. Bilateral pulmonary embolism with infection;

iii. Multiple mercury resides in right atrium/ ventricles and abdomen;

iv. Toxic organ damage in heart, liver and kidneys.

After admission to hospital, immediately we gave sodium dimercaptopropane sulfonate (DMPS) 0.25 $\mathrm{g}$ q6h, and then changed to $\mathrm{q} 8 \mathrm{~h}$ three days later and q12h one week later. At the same time, dialysis, energy supplementation, anti-inflammatory therapy and supporting treatment was given. About 2000-3500 ml fluid per day was given to him on average. Meanwhile, $\mathrm{X}$-ray revealed there was no light metal substance after dialysis.

After one week of treatment, the bloody sputum stopped, and his liver and renal functions recovered. However, he had dyspnea with light activity, accompanied with sweating, salivation, and sometimes with mental abnormalities such as screaming, weepings, easy irritating and groaning. He was in the hospital for 73 days. During this hospitalization, he received $32.5 \mathrm{~g}$ DMPS. He was discharged in stable from condition hospital. In outpatient clinic, he was given DMPS of $0.25 \mathrm{~g}$ qod for 4 cycles, every 4 weeks with 10 days interruption for each cycle. After 4 cycles, therapy cycle was changed to every half year, with co-treatment with vitamins. During the following period, he complained of low-grade fever, cough and dyspnea, and gradually symptoms of toxic encephalopathy appeared. In March 2003, he felt trembling in both upper limbs. Symptoms could not be controlled after treatment with methyldopa, and dyspnea was more and more aggravated. He was admitted again in May, 2003. Physical examination showed stable vital signs, with aphthenxia, slow response, asaphia and mood instability, shaking in both upper limbs, and light trembling in lower limbs, instability in gait, big step length, choreic movement with hypermyotonia but normal tendon reflexes. Skull CT did not appear any abnormal changes. EEG showed moderate abnormal. Chest X-ray showed opaque material present diffusely in both lung fields, without any absorption compared to before treatment images. He was diagnosed as chronic mercury poisoning, toxic encephalopathy and pulmonary infection. Again, he was given DMPS 0.25 g, Qd, cytidine diphosphate choline (CDPC), vitamin B1 to promote the metabolism of brain cells and anti-infection therapy for 39 days. In total, he received DMPS for 14.25 and his conditions got better. However, ten days after discharge he was found dead at home.

\section{DISCUSSION}

Metallic mercury poisoning is a common occupational disease, which seldom occurres in daily life. Previously, the major clinical manifestations were oral mucosal lesions and renal injury in acute phase and mental symptoms in chronic phase $[2,3]$. With deep research, we gradually found that metallic mercury poisoning could

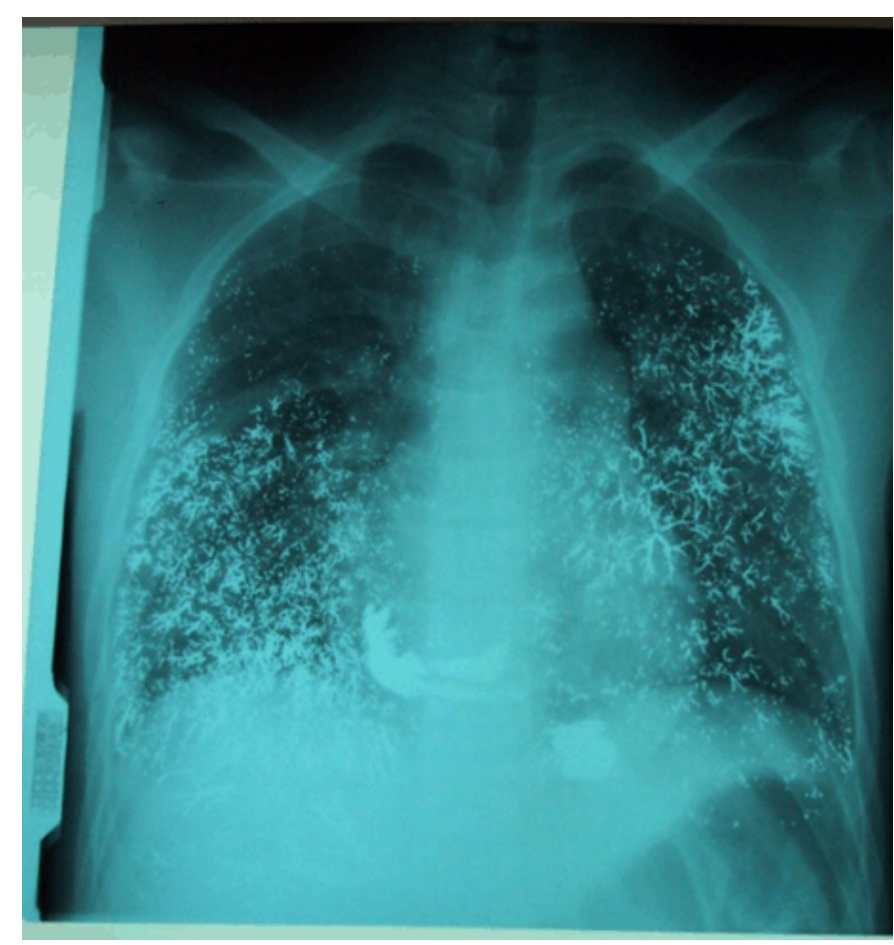

Figure 1: Chest X-ray in anteroposterior position showing metallic substance. 
cause multiple organ dysfuction syndrome (MODS), involving nerve, renal, and digestive systems [4], even sometimes combined with hypertension and arrhythmia. DMPS is the standard therapy to prevent HODS.

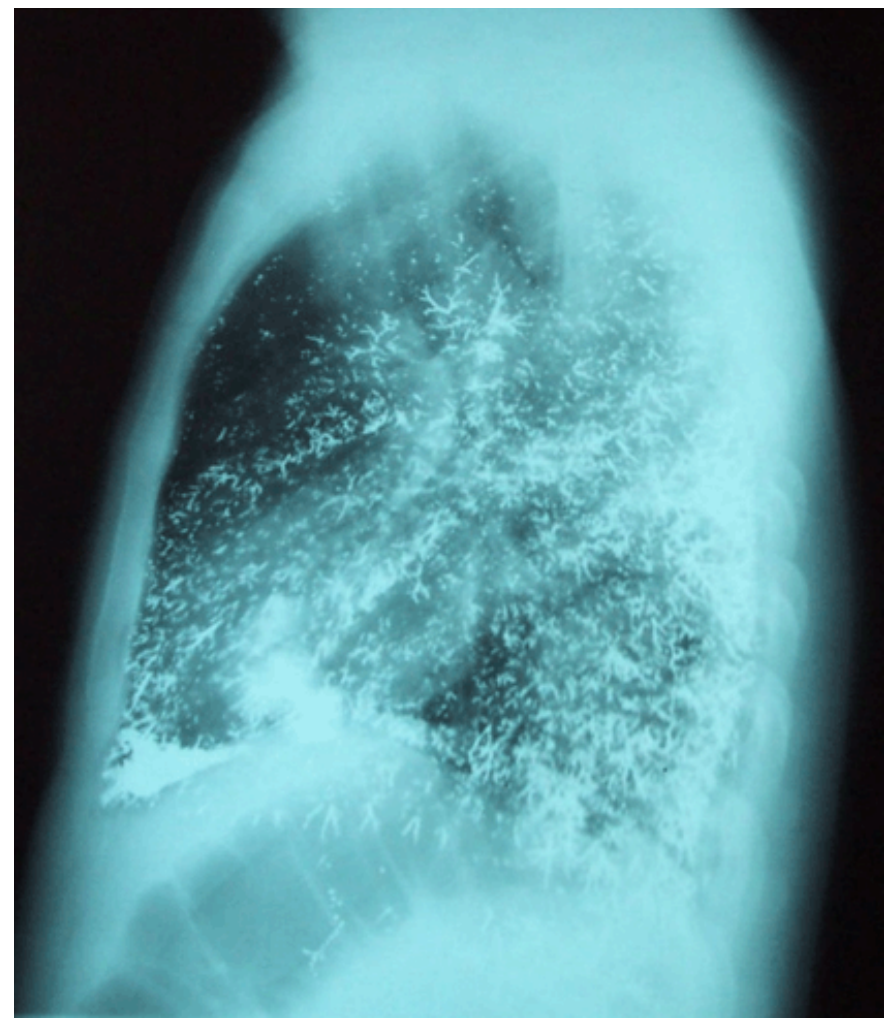

Figure 2: Chest X-ray in lateral position showing metallic substance.

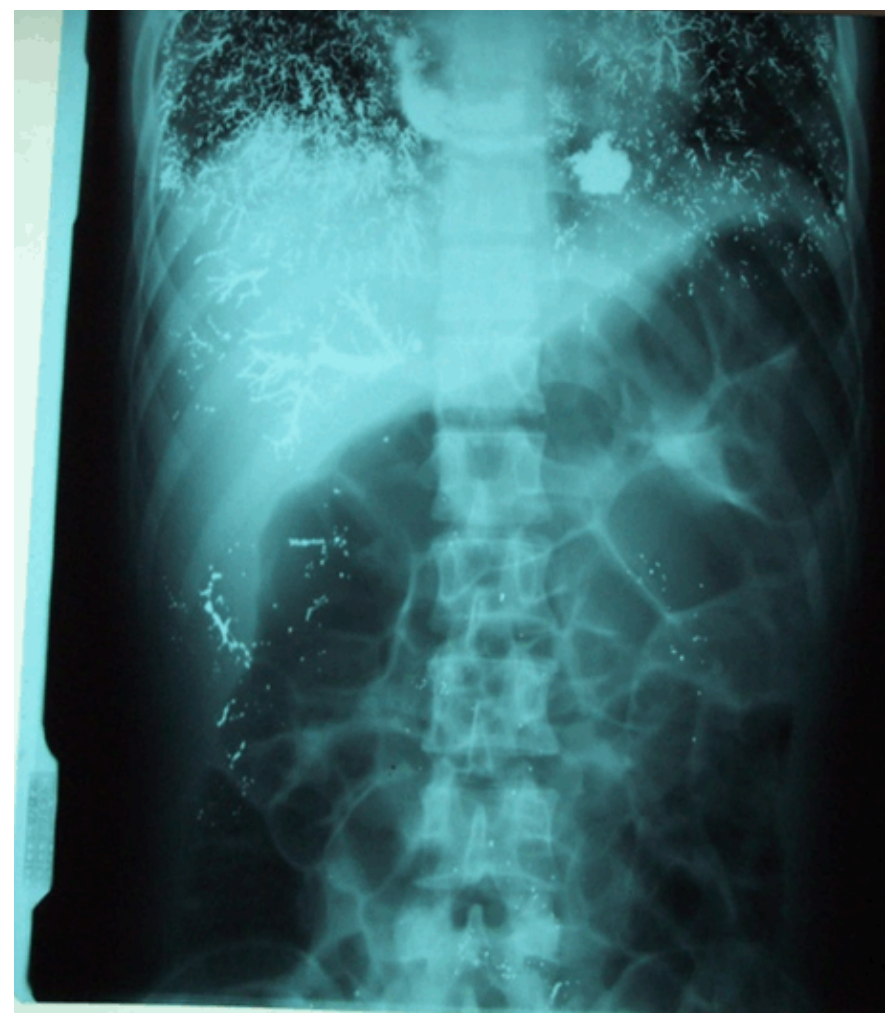

Figure 3: Abdomen X-ray in anteroposterior position showing metallic substance.
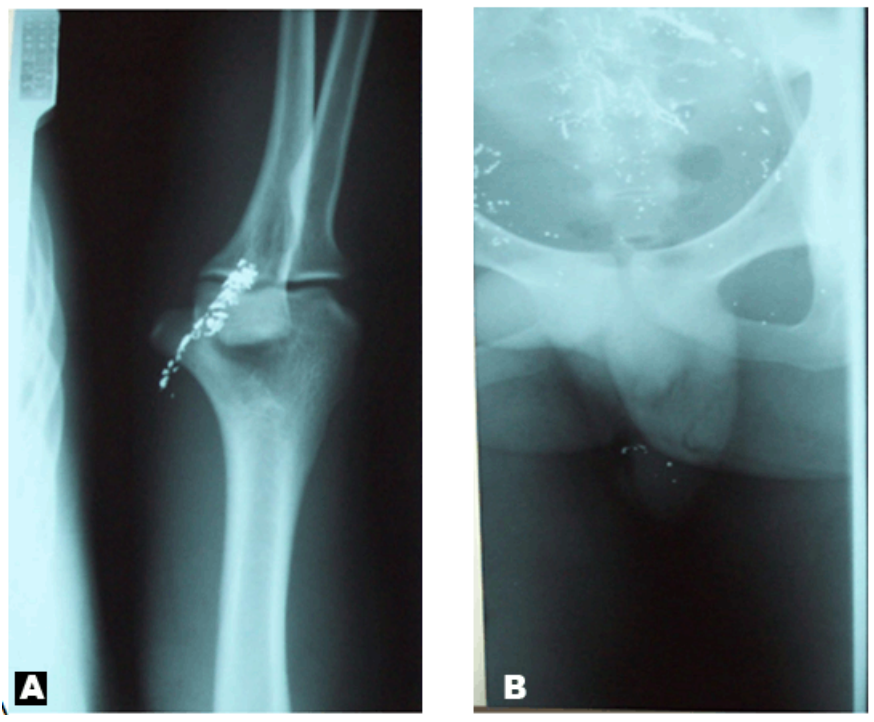

Figure 4: (A) X-ray of left limb and (B) pelvis.

Mercury exists in three forms: elemental mercury, organic mercury, and inorganic mercury. Elemental mercury is a silvery liquid at room temperature. Organic mercury compounds are formed when mercury combines with carbon. Inorganic mercury compounds are formed when mercury combines with other elements, such as sulfur or oxygen, and can occur naturally in the environment. Microscopic organisms in water and soil can convert elemental and inorganic mercury into an organic mercury compound, which accumulates in the food [5]. Mercury can be absorbed into the body through inhalation, ingestion, absorption through skin, and injection. Intravenous mercury injection is usually seen in suicide attempts.

Mercury poisoning is a rare but fatal toxicologic emergency. Neurologic manifestations involving the central nervous system are seen usually with chronic mercury intoxication. The most commonly seen complaints are headache, tremor, impaired cognitive skills, weakness, muscle atrophy, and paresthesia [6]. In our case it appeared mainly with neurologic manifestations which was typical. What is less reported is that the patients revealed cardiac symptom and chest $\mathrm{X}$-ray showed obvious mercury deposition in atrium and ventricles.

We think his bad clinical outcome was related to the huge volume of injected metallic mercury, in addition to the long half-life. It has been reported that a man took 2500 g metallic mercury orally, and then had vomited $500 \mathrm{~g}$ mercury immediately [7]. Vacuum aspiration of $600 \mathrm{~g}$ mercury from stomach was done through gastroscope. Penicillamine therapy was given for two months and the patient had a good prognosis [7]. From this example, we may conclude, that for metallic mercury poisoning with huge volume, only drug therapy may not 
enough. Nowadays, was vascular intervention therapy becomes more and more matured, maybe in acute period of mercury poisoning, we can try to remove mercury via vascular intervention therapy, combined with drug therapy at the same time. This may improve the clinical outcome.

\section{CONCLUSION}

In cases of hydrargyrism with huge volume, only drug therapy may not enough. Nowadays, vascular intervention therapy may be more effective in acute period, which can get rid the residual mercury. This may improve the clinical outcome.

\section{Author Contributions}

Yinglu Hao - Substantial contributions to conception and design, Acquisition of data, Analysis and interpretation of data, Drafting the article, Revising it critically for important intellectual content, Final approval of the version to be published

Yanping Li - Analysis and interpretation of data, Revising it critically for important intellectual content, Final approval of the version to be published

\section{Guarantor}

The corresponding author is the guarantor of submission.

\section{Conflict of Interest}

Authors declare no conflict of interest.

\section{Copyright}

(C) 2016 Yinglu Hao et al. This article is distributed under the terms of Creative Commons Attribution License which permits unrestricted use, distribution and reproduction in any medium provided the original author(s) and original publisher are properly credited. Please see the copyright policy on the journal website for more information.

\section{REFERENCES}

1. Nordberg M, Nordberg GF. Toxicological aspects of metallothionein. Cell Mol Biol (Noisy-le-grand) 2000 Mar;46(2):451-63.

2. Zhang S, Huitai S, liping C, et al. 107 cases of treatment of mercurialism. Industrial Health and Occupational Diseases 2014;6(40):471.

3. Tang Y, Wang X, Jia J. Mercury poisoning presenting as sporadic Creutzfeldt-Jakob disease: a case report. Ann Intern Med 2015 Mar 17;162(6):462-3.

4. Huang X, Law S, Li D, Yu X, Li B. Mercury poisoning: a case of a complex neuropsychiatric illness. Am J Psychiatry 2014 Dec 1;171(12):1253-6.

5. Andersen O, Aaseth J. A review of pitfalls and progress in chelation treatment of metal poisonings. J Trace Elem Med Biol 2016 Apr 9. pii: So946672X(16)30031-1.

6. Gençpinar P, Büyüktahtakin B, Ibisoglu Z, Genç S, Yilmaz A, Mihçi E. Mercury poisoning as a cause of intracranial hypertension. J Child Neurol 2015 May;30(6):760-3.

7. Zheng Y, Dewang C, Xiang W, et al. Massive volume of mercurialism: a case report. Clinical emergency journal 2000;1(4):163.
Access full text article on other devices

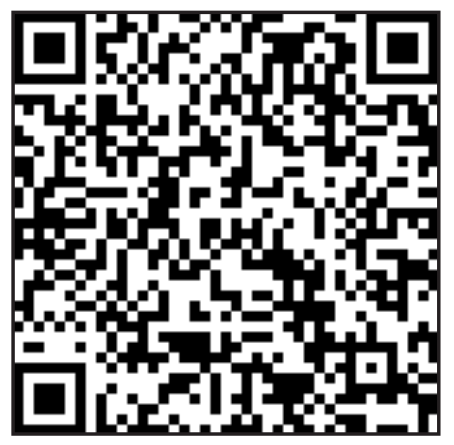

Access PDF of article on other devices

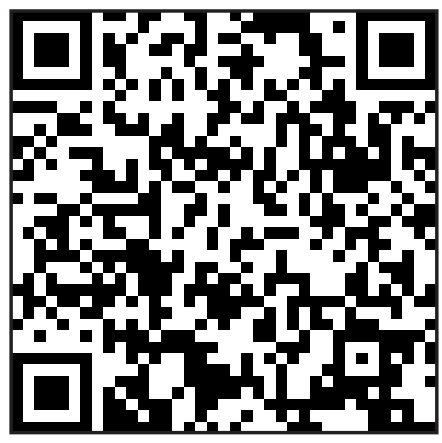

